
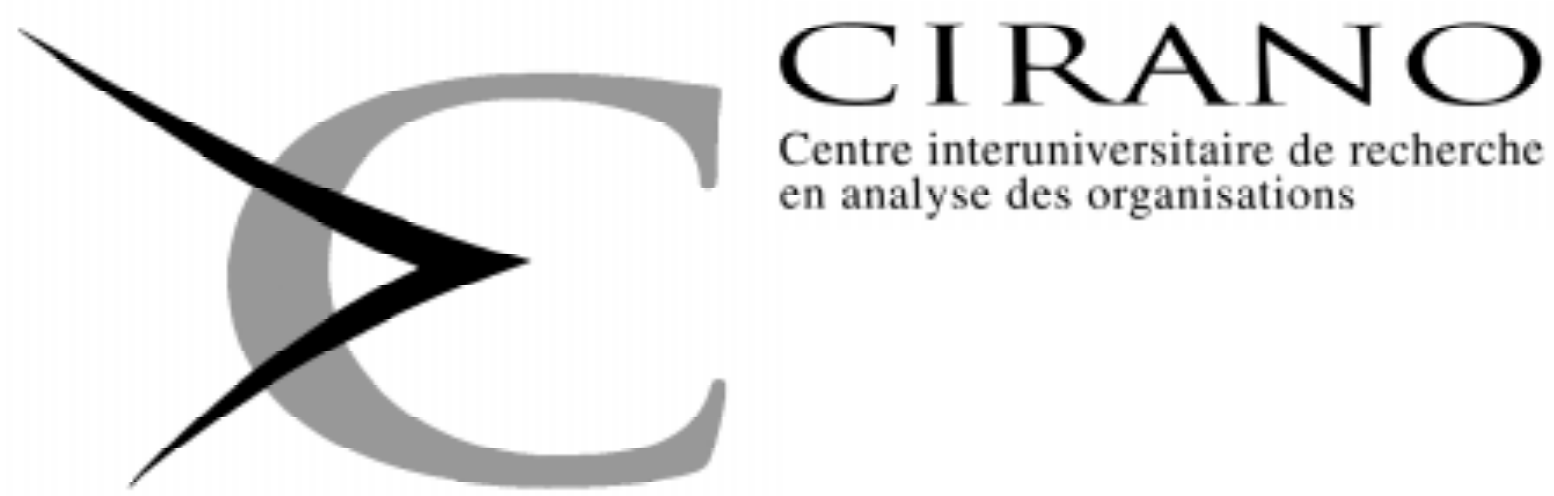

Centre interuniversitaire de recherche en analyse des organisations

Série Scientifique

Scientific Series

$96 s-34$

Structural Change and

Asset Pricing in

Emerging Markets

René Garcia, Eric Ghysels 


\section{CIRANO}

Le CIRANO est une corporation privée à but non lucratif constituée en vertu de la Loi des compagnies du Québec. Le financement de son infrastructure et de ses activités de recherche provient des cotisations de ses organisations-membres, d'une subvention d'infrastructure du ministère de l'Industrie, du Commerce, de la Science et de la Technologie, de même que des subventions et mandats obtenus par ses équipes de recherche. La Série Scientifique est la réalisation d'une des missions que s'est données le CIRANO, soit de développer l'analyse scientifique des organisations et des comportements stratégiques.

CIRANO is a private non-profit organization incorporated under the Québec Companies Act. Its infrastructure and research activities are funded through fees paid by member organizations, an infrastructure grant from the Ministère de l'Industrie, du Commerce, de la Science et de la Technologie, and grants and research mandates obtained by its research teams. The Scientific Series fulfils one of the missions of CIRANO: to develop the scientific analysis of organizations and strategic behaviour.

\section{Les organisations-partenaires / The Partner Organizations}

-École des Hautes Études Commerciales.

-École Polytechnique.

-McGill University.

-Université de Montréal.

-Université du Québec à Montréal.

-Université Laval.

-MEQ.

-MICST.

-Avenor.

-Banque Nationale du Canada.

-Bell Québec.

-Fédération des caisses populaires de Montréal et de l'Ouest-du-Québec.

-Hydro-Québec.

-La Caisse de dépôt et de placement du Québec.

-Raymond, Chabot, Martin, Paré.

-Société d'électrolyse et de chimie Alcan Ltée.

-Téléglobe Canada.

- Ville de Montréal.

Ce document est publié dans l'intention de rendre accessibles les résultats préliminaires de la recherche effectuée au CIRANO, afin de susciter des échanges et des suggestions. Les idées et les opinions émises sont sous l'unique responsabilité des auteurs, et ne représentent pas nécessairement les positions du CIRANO ou de ses partenaires.

This paper presents preliminary research carried out at CIRANO and aims to encourage discussion and comment. The observations and viewpoints expressed are the sole responsibility of the authors. They do not necessarily represent positions of CIRANO or its partners.

ISSN 1198-8177 


\title{
Structural Change and Asset Pricing in Emerging Markets*
}

\author{
René Garcia ${ }^{\dagger}$, Eric Ghysels ${ }^{\ddagger}$
}

\section{Résumé / Abstract}

\begin{abstract}
Dans cet article, nous montrons l'importance d'utiliser des tests de changement structurel dans le contexte des marchés boursiers en émergence. Les modèles de valorisation des actifs financiers utilisés dans ce contexte sont en général des modèles conditionnels à facteurs fondés sur des facteurs à caractère international tels les rendements excédentaires sur le marché mondial des actions, les écarts de taux captant la prime de risque et la prime de terme, ainsi que d'autres variables visant à mesurer les fluctuations du cycle économique mondial. Nous montrons que dans de nombreux pays, bien que nous ne puissions pas rejeter les modèles en fonction des tests de suridentification habituels de distribution chi-carré, nous les rejetons en fonction des tests de changement structurel, notamment lorsque nous utilisons des facteurs internationaux. Nous trouvons des résultats beaucoup plus favorables aux modèles et une plus grande stabilité lorsque nous testons un CAPM local avec des portefeuilles ordonnés selon la taille. Un effet de taille persiste toutefois dans certains pays.

This paper documents the importance of testing for structural change in the context of emerging markets. Typically, asset pricing factor models for emerging markets are conditioned on world financial market factors such as world equity excess returns, risk and maturity spreads as well as other variables designed to capture world business cycle fluctuations. We show that for many countries, while we cannot reject the model according to one usual chi-square test for overidentifying restrictions, we reject it on the basis of structural change tests, especially when international factors are considered. Much better support and greater stability are found when a local CAPM is tested with size-ranked portfolios. Some evidence of a small-size effect persists for some countries.
\end{abstract}

\footnotetext{
" Correspondence Address: René Garcia, CIRANO, 2020 University Street, 25th floor, Montréal, Qc, Canada H3A 2A5 Tel: (514) 985-4014 Fax: (514) 985-4039 e-mail: garciar@ cirano.umontreal.ca Financial support by the PARADI Research Program funded by the Canadian International Development Agency (CIDA) is gratefully acknowledged. Invaluable research assistance has been provided by Benoit Durocher.

${ }^{\dagger}$ Université de Montréal, CRDE and CIRANO

¥ Pennsylvania State University and CIRANO
} 
Mots Clés : $\quad$ Modèles à facteurs conditionnels, marchés émergents, changements structurels

Keywords : Conditional Factor Models, Time-Varying Risk and Returns, Emerging Markets, Structural Stability

JEL : G12, G15 


\section{Introduction}

Investors and the financial press have in the last few years paid considerable attention to the new equity markets that have emerged around the world. This new interest has undoubtedly been spurred by the large, and in some cases huge returns offered by these markets. Fundamental asset pricing models such as the CAPM and the APT tell us that high expected returns ought to be associated with high measures of risk with respect to a number of risk factors. One would therefore want to identify the set of fundamental sources of risk that affect the returns in these emerging markets. Two different views can be taken when searching for these factors: one can consider that these markets are segmented and concentrate on local risk factors to explain local returns, or one can adopt the perspective of an international investor diversifying his portfolio worldwide. If enough investors diversify internationally their portfolios and markets move towards integration, expected returns in one country will be well described by the country's world risk exposure, defined as the covariance of the country's returns with the world market portfolio. This is the view taken by Harvey $(1991,1995)$ in two recent studies, one on industrialized countries, the other on emerging markets. ${ }^{1}$

In both studies, the author adopts a dynamic factor asset pricing model in which the risk loadings are measured with respect to the world market return in excess of a risk-free asset return. Moreover, these risk loadings are allowed to vary through time. This feature is clearly essential in the context of emerging markets where the internal dynamics underlying the country's returns index along with unstable macroeconomic and political conditions can bring considerable variation in the factor loadings. This variability is brought into the model by the projection of both the country's returns and the world returns on a set of variables deemed to be in the information set of investors. However, the coefficients of these projections are maintained constant over the sample period. In other words, the returns are linked to these information variables through a stable relationship. This assumption can be seriously questioned in a model for emerging markets since many reasons can be invoked for the presence of structural changes. Market liberalization measures can be introduced at one or various points in the sample, drastic political or economic policy changes can take place, or new institutions can be set in place. In this context, one would like to have a test

\footnotetext{
${ }^{1}$ Bekaert and Harvey $(1995,1996)$ develop models of the conditional mean and conditional variance of returns which allows for time-varying influences of both local and world factors. These models address some of the issues that are discussed in this paper.
} 
for the stability of the projection coefficients on the different variables.

In this paper, we apply tests for structural stability to two leading conditional factor models: (1) a conditional CAPM model similar to Harvey $(1991,1995)$; (2) conditional factor models on a set of size portfolios for each country. The second model can be viewed as a refinement of the first. These models have been estimated via the generalized method of moments (GMM) procedure discussed in Hansen (1982). The success of the model fit is judged according to GMM-based criteria. In particular, one tests whether the overidentifying restrictions imposed by the model agree with the data. The fundamental problem is that overidentifying restriction tests are not designed to diagnose whether a model provides a stable time invariant relationship between the return and the information variables. Technically speaking, one can easily face a situation where a model's overidentifying restrictions are not rejected, while the projection parameters of returns on the information set vary through time. Indeed, the method of moments approach will conceal the time variation in these coefficients as the GMM estimator will converge to some sort of sample average. ${ }^{2}$ It may parenthetically be noted that such observations are not confined to the context of emerging markets, as shown for instance by Ghysels (1996) for US and other stock markets.

The first model is tested on the stock market index returns of each emerging market with respect to a world index. The conditional factor models on size portfolios in each country have a two-fold purpose: (1) uncover whether a local conditional CAPM holds in each country, in other words test if the markets are segmented, or (2) if foreign factors also play a role, and therefore conclude that emerging markets are semiintegrated. For the CAPM model, it is to the best of our knowledge the first test of this central theory in finance in the context of emerging markets. This is the reference model with which to compare the results obtained with the US markets both in terms of acceptance or rejection of the model and of the presence of anomalies such as the small size effect.

Our results show that models relating the emerging market index or portfolio returns to world or US returns are in general unstable, while local models relating size portfolio returns to the local market portfolio are stable and surprisingly supportive of the CAPM theory in about half of the countries, while the size anomaly appears in others.

In section 2 we briefly describe the dynamic asset pricing models inspired by Harvey $(1991,1995)$ and Ferson and Korajczyk (1995) and

\footnotetext{
${ }^{2}$ In an econometrics jargon this means that overidentifying restrictions tests do not have (local asymptotic) power against alternatives characterized by parameter variation. This is formally shown in Ghysels and Hall (1990a). They also provide several examples using the consumption-based CAPM.
} 
we discuss the structural change test. The empirical results for the various models appear in section 3 . The paper concludes with section 4 .

\section{Asset Pricing and Structural Change Anal- $\mathrm{ysis}^{3}$}

For the purpose of our discussion, we will use a simplified version of the conditional CAPM:

$$
E\left[r_{i t+1} \mid Z_{t}\right]=\beta_{i t} E\left[r_{M t+1} \mid Z_{t}\right]
$$

where $r_{M t+1}$ denotes the excess return from $t$ to $t+1$ on the market portfolio and $r_{i t+1}$ the excess return on any asset or portfolio of assets $i$. The variable $Z_{t}$ belongs to the information set of the agent and $\beta_{i t}$ is the time-varying market beta of portfolio $i$. This time variation of market betas is documented in Harvey (1989), Ferson and Harvey $(1991,1995)$ and Ferson and Korajczyk (1995). The conditional CAPM model defines the market beta as the ratio of the conditional covariance of the portfolio return with the market return to the variance of the market return:

$$
\beta_{i t}=\frac{E\left[\left(r_{M t+1}-E\left[r_{M t+1} \mid Z_{t}\right]\right)\left(r_{i t+1}-E\left[r_{i t+1} \mid Z_{t}\right]\right) \mid Z_{t}\right]}{E\left[\left(r_{M t+1}-E\left[r_{M t+1} \mid Z_{t}\right]\right)^{2} \mid Z_{t}\right]}
$$

The expectations are obtained via the projection equations:

$$
\begin{aligned}
E\left[r_{i t+1} \mid Z_{t}\right] & =\delta_{i} Z_{t} \\
E\left[r_{M t+1} \mid Z_{t}\right] & =\delta_{M} Z_{t}
\end{aligned}
$$

From (2.2) we learn that two fixed parameters, namely $\delta_{M}$ and $\delta_{i}$, together with $Z_{t}, r_{m}$ and $r_{i}$ determine the time variation in $\beta_{i t}$.

The question we are interested in is whether this particular (or any other) characterization of $\beta_{i t}$ is adequate and does not yield a systematic mispricing of risk factors. Combining equations (2.1) and (2.3) we can write the asset pricing equation as follows:

$$
r_{i t+1}=\beta_{i t} \delta_{M} Z_{t}+u_{i t+1}
$$

\footnotetext{
${ }^{3}$ In this section we follow some of the analysis in Ghysels (1996).
} 
where $E u_{i t+1} Z_{t}=0$. If the restrictions of the conditional CAPM do not hold, so that beta risk is inherently misspecified, we obtain as a generic alternative:

$$
r_{i t+1}=\tilde{\beta}_{i t} \tilde{\delta}_{M t} Z_{t}+\tilde{u}_{i t+1}
$$

with $E \tilde{u}_{i t+1} Z_{t}=0$ and $\tilde{\beta}_{i t} \neq \beta_{i t}$ is obtained from (2.2) replacing $\delta_{M}$ by $\tilde{\delta}_{M t}$ and $\delta_{i}$ by $\tilde{\delta}_{i t}{ }^{4}$

To know whether the conditional CAPM is the source of modelling error, we describe in the remainder of this section a particular strategy which appears natural when time variation of parameters is the main concern and focus of the model. The time varying betas can be misspecified either (1) because of the chosen instrument $Z_{t} ;(2)$ because of its functional form $\beta(\cdot)$ or (3) a combination of both. Instead of trying different instruments and investigating alternative functional forms the analysis in Ghysels (1996) focused directly on a key assumption which drives time varying beta models. One rather explicit way of testing whether (2.1) is an adequate model in the pricing of asset returns amounts to testing the hypothesis:

$$
H_{o}: \begin{cases}\tilde{\delta}_{M t}=\delta_{M} & \forall t=1, . ., T \\ \tilde{\delta}_{i t}=\delta_{i} & \forall t=1, . ., T\end{cases}
$$

so that the sole time variation in beta is that determined by the model.

It is almost natural to consider hypothesis (2.6) since the original motivation for conditional CAPM models was non-constancy of parameters. Hence, the issue is only satisfactorily addressed when the model for beta no longer involves time varying parameters. Moreover, in the context of emerging markets, this hypothesis comes even more naturally because of the changing economic environment.

Anyone familiar with the empirical evidence may find it surprising that there is a need to test (2.6) because conditional CAPM and APT models for developed and emerging markets alike are typically well supported by the data. To clarify this we have to stress that testing the hypothesis in (2.6) is far more stringent than the usual overidentifying restrictions tests, often called J-statistics, that have been used to diagnose the fit of an asset pricing model like the conditional CAPM. Since

\footnotetext{
${ }^{4}$ This generic altenative emphasizes the fact that the specification of $\beta_{i t}$ is erroneous. Other sources of misspecification, such as omitted factor risk are, at least for the moment, not considered here. No specific laws for $\tilde{\delta}_{M t}$ or $\tilde{\delta}_{i t}$ and hence $\tilde{\beta}_{i t}$ will be used for the moment.
} 
such models are estimated via GMM let us proceed by specifying the moment conditions of the model. Namely, equations (2.2), (2.3), (2.4) and (2.5) together yield that:

$$
E\left(\begin{array}{c}
r_{i t+1}-\tilde{\delta}_{i t} Z_{t} \\
r_{M t+1}-\tilde{\delta}_{M t} Z_{t} \\
\tilde{\delta}_{i t} Z_{t}\left[\left(r_{M t+1}-\tilde{\delta}_{M t} Z_{t}\right)^{2}\right]-\left(r_{M t+1}-\tilde{\delta}_{M t} Z_{t}\right)\left(r_{i t+1}-\tilde{\delta}_{i t} Z_{t}\right) \tilde{\delta}_{M t} Z_{t}
\end{array}\right) Z_{t}=0
$$

The formulation in (2.7) represents the set of moment conditions involved in the GMM estimation procedure but does not impose the null hypothesis $(2.7)$ of constant parameters. The models proposed by Bekaert and Harvey $(1995,1996)$ could be viewed as belonging to this class, but they assume a very specific model for the time variation of the parameters. The estimation of the conditional CAPM imposing fixed parameters $\delta_{M}$ and $\delta_{i}$ while the data are generated by (2.7) will yield GMM parameter estimates $\bar{\delta}_{M}$ and $\bar{\delta}_{i}$ which are some sort of sample averages of the underlying $\tilde{\delta}_{M t}$ and $\tilde{\delta}_{i t}$. Ghysels and Hall (1990b) show formally that overidentifying restrictions tests based on the moment conditions such as those in (2.7) but evaluated at fixed parameter estimates $\bar{\delta}_{M}$ and $\bar{\delta}_{i}$ have a tendency not to reject the model. This problem is not just a theoretical curiosity. Indeed, we will provide numerous examples where this situation occurs in empirical asset pricing models. Hence, the usual diagnostic tests to judge the validity of a model are not adequate to detect systematic mispricing of asset returns because of erroneous beta dynamics.

How do we go about testing for structural invariance of the model, i.e. verify whether (2.6) holds? As one can imagine, there are many ways to do this. Probably the simplest is to assume as an alternative that at some point in the sample there is a structural break, like for instance :

$$
\widetilde{\delta}_{j t}=\left\{\begin{array}{ll}
\delta_{j 1} & t=1, \ldots, \pi T \\
\delta_{j 2} & t=\pi T+1, \ldots, T
\end{array} \quad j=M, i\right.
$$

where $\pi$ determines the fraction of the sample before and after the assumed break point. ${ }^{5}$ If the break point $\pi T$ were known our task would

\footnotetext{
${ }^{5}$ It is worth noting that in (2.6) all parameters are tested jointly for stability. In several circumstances, however, the parameters involved play different roles and therefore depending on which ones are unstable, a different interpretation should be given. For instance, in the multifactor models which will be discussed later, one has a set of parameters that arise from purely ancillary statistical assumptions regarding projection equations besides parameters with an economic interpretation. To emphasize this distinction we will often conduct tests involving only a subset of the parameter vector. For the moment, however, we will proceed with discussing tests involving the entire vector.
} 
be relatively easy to perform. Estimating $\delta_{j 1}$ and $\delta_{j 2}$ and comparing both estimates to see whether they are significally different would be one way to proceed, which is often referred to as a Chow test. Unfortunately, in the present context we do not really want to assume $\pi$ known. In recent years several procedures have been advanced to test the null hypothesis (2.6) against the alternative like (2.8) with unknown break point $\pi$. In the Appendix to the paper we provide a detailed description of the econometric procedures that were developed for GMM estimators by Andrews (1993). In the remainder of the section we will explain what these procedures amount to without actually providing any of the technical details. To facilitate our presentation let us denote parameter estimates for $\delta_{j h}, h=1,2, j=i, M$ associated with a particular presumed break point $\pi T$ as $\widetilde{\delta}_{j h}(\pi)$. Suppose now that we construct for each possible break point $\pi$ a test for structural change based on $\widetilde{\delta}_{j h}(\pi)$, $h=1,2 .{ }^{6}$ Hence, for each break point $\pi$ we have a Wald-type statistic $W(\pi)$ based on the two estimates before and after the break $\pi T$. The idea now is to combine the Wald statistics for all possible break points $\{\mathrm{W}(\pi), \pi \in[.2, .8]\}$ into a single test statistic. This can be done in a variety of ways. A first possibility is to take the maximum over $\pi$ of all $\mathrm{W}(\pi)$ values, called SupW where Sup stands for supremum. Andrews (1993) suggested this type of test and tabulated its distribution under the null hypothesis appearing in (2.6).

The SupW test may be intuitively appealing as it picks the maximum evidence for a structural break. It is however not the only statistic one can think of. First, it should be noted that we prefer to use the SupLM test, that is to say the supremum Lagrangian Multiplier test rather than the Supremum Wald test simply because the former requires far less computations. Indeed, to calculate the SupLM which is formally presented in equation (A.6) appearing in the Appendix, one does not compute all the parameter estimates $\widetilde{\delta}_{j h}(\pi)$ for each of the subsamples. Instead, the parameter estimates $\bar{\delta}_{M}$ and $\bar{\delta}_{i}$ obtained from the full sample are used. This saves an enormous amount of computer time by avoiding all the (nonlinear) GMM parameter estimations. Since a great number of asset pricing models will be tested, computational efficiency has strong appeal. Second, the statistical properties of the SupLM test are at least

\footnotetext{
${ }^{6}$ We have to leave a certain number of observations at each end of the sample in order to estimate $\widetilde{\delta}_{j 1}$ and $\widetilde{\delta}_{j 2}$. We can test for instance between $.2 T$ and $.8 T$. Therefore we have in this particular case $20 \%$ of the sample trimmed at each end. The trimming percentage determines how many observations are used to compute the first estimate $\widetilde{\delta}_{j 1}(\pi)$ and last estimate $\widetilde{\delta}_{j 2}(\pi)$ with $\pi=.2 T$ and $\pi=.8 T$ respectively. The sample sizes $T$ involved in our empirical applications made $20 \%$ a reasonable choice.
} 
as good, if not better, than those of the SupW test (see the Appendix for details).

One may wonder by now why we focus exclusively on tests having a single break point as alternative. Surely, there are many other types of structural instabilities, like for instance cases where there are several breaks or where there are gradual movements in the $\delta_{i k}$ parameters. Constructing tests against all possible types of instabilities is simply impossible both statistically and practically. Fortunately, however, the situation is not hopeless because the single unknown break point statistics have power against a large class of parameter instability patterns far beyond what appears explicitly as alternative in (2.8). Therefore, examining (only) single break point tests goes a long way towards our goal.

In the next section, we present the models which will be considered in our empirical study.

\section{The Conditional Asset Pricing Models Used for Emerging Markets}

To apply our structural stability analysis to asset pricing models for emerging markets, we will consider two sets of models, namely the conditional CAPM in the spirit of Harvey $(1991,1995)$ and a conditional factor model similar to Ferson and Korajczyk (1995)). The proposed version of the conditional CAPM is the simplest one. It links the expected returns for stock markets in a set of countries to the expected returns on a world market portfolio via their conditional beta. It is the model we described in Section 2, except that $Z_{t}$ does not represent a single variable, but a set of conditioning variables or instruments. This conditional CAPM model states that:

$$
E\left[r_{i t+1} \mid \Omega_{t}\right]=\frac{\operatorname{Cov}\left[r_{i t+1}, r_{M t+1} \mid \Omega_{t}\right]}{\operatorname{Var}\left[r_{M t+1} \mid \Omega_{t}\right]} E\left[r_{M t+1} \mid \Omega_{t}\right]
$$

where $r_{i t+1}$ is the return on the market of country $i, r_{M t+1}$ the return on the world portfolio and $Z_{t}$ the available information at time $t$. To make equation (3.1) operational, we define a set of projections, namely:

$$
\begin{gathered}
E\left[r_{i t+1} \mid \Omega_{t}\right]=Z_{t}^{\prime} \delta_{i} \\
E\left[r_{M t+1} \mid \Omega_{t}\right]=Z_{t}^{\prime} \delta_{M}
\end{gathered}
$$


where $Z_{t}$ is a $L \times 1$ vector of instruments and the vectors $\delta_{i}$ and $\delta_{M}$ are (stable) parameter $(L \times 1)$ vectors defining the projections. One obtains a set of moment conditions suitable for GMM estimation of $\delta_{i}$ and $\delta_{M}$ via:

$$
E\left(\begin{array}{c}
\left(r_{i t+1}-Z_{t}^{\prime} \delta\right) \\
\left(r_{M t+1}-Z_{t}^{\prime} \delta_{M}\right) \\
\left(u_{M t+1}^{2} Z_{t}^{\prime} \delta_{i}-u_{M t+1} u_{i t+1} Z_{t}^{\prime} \delta_{M}\right)
\end{array}\right) \otimes Z_{t}^{\prime}=0
$$

where $u_{i t+1}=r_{i t+1}-Z_{t}^{\prime} \delta_{i}$ and $u_{M t+1}=r_{M t+1}-Z_{t}^{\prime} \delta_{M}$.

It should be noted that this specification differs from the model in Harvey (1995) when an exactly identified system of equations is specified. Two equations are added to system (3.4) to capture an average pricing error, while $Z_{t}^{\prime} \delta_{i}$ is replaced by $Z_{t}^{\prime} k_{i}$ where $k_{i}$ are free parameters. $^{7}$ Our system of equations (3.4) can be seen as the minimal set of equations required to test a conditional CAPM with projections on economic variables.

We also consider a factor model where the asset returns $r_{i t+1}$ represent the returns on a set of size portfolios and where we will use either the local market portfolio alone as a factor (the segmentation hypothesis) or the local market portfolio in conjunction with external factors (the semi-integration hypothesis). This model is a conditional factor model similar to Ferson and Korajczyk (1995) who undertook a very thorough empirical investigation of risk and return for the U.S. using a multifactor conditional APT. The setup is very similar to the conditional CAPM described above except that the moment conditions are a bit more elaborate because of the presence of a set of portfolios and factors. The set of moment conditions is defined as follows:

$E\left[\begin{array}{c}r_{i t+1}-Z_{t}^{\prime} \delta_{i} \\ \left(F_{t+1}^{\prime}-Z_{t}^{\prime} \gamma_{i}\right)^{\prime} \\ \left(F_{t+1}^{\prime}-Z_{t}^{\prime} \gamma_{i}\right)^{\prime}\left(F_{t+1}^{\prime}-Z_{t}^{\prime} \gamma_{i}\right) \beta_{i}-F_{t+1}\left(r_{i t+1}-Z_{t}^{\prime} \delta_{i}\right)\end{array}\right] \otimes Z_{t}^{\prime}=0$

where $F_{t+1}^{\prime}$ is a $K \times 1$ vector of factor portfolios, $\beta_{i}$ is a $K \times 1$ vector of the betas for portfolio $i$ and $Z_{t}$ is an $(L \times 1)$ vector of instruments. When using as factors both local and external variables, the overidentification tests of the model can be interpreted as a test for the semi-integration of

\footnotetext{
${ }^{7}$ This assumes that the conditional beta is a linear function of the information variables $Z_{t}$.
} 
the emerging markets. Uncovering instability in this model could mean that the integration of emerging markets into the world market has occurred in various steps and therefore that the weights of the world and local market factors could have changed over time for valuing portfolios. It is important to note here that in contrast to the conditional CAPM, the model defined in (3.5) has parameters which play a very different role. It makes hypothesis testing also more interesting. Indeed, this more elaborate model has the advantage of separating projection equations and asset pricing moment conditions involving conditional betas. In (3.4) the third set of moment conditions does not involve any new parameters while in (3.5) the third set involves explicitly parameterized betas. The parameters $\delta_{i}$ and $\gamma_{i}$ arise from purely ancillary statistical assumptions. Their instability means we have misspecified the projection equations. The instability of $\beta_{i}$, however, has a very different meaning and implication. These are the most interesting parameters from an asset pricing perspective.

\section{Empirical Results}

The dynamic asset pricing models described in Section 3 will be estimated for the following set of emerging markets: Argentina, Brazil, Chile, Mexico, India, Korea, Thailand, Greece, Jordan and Zimbabwe. The returns on each country's index or sets of portfolios were computed from the data provided in the Emerging Market Data Base (EMDB) of the International Finance Corporation which is part of the World Bank. For the return series computed with the IFC data bank, the data were available on a monthly basis from January 1976 through December 1992, a total of 204 observations. Some sample moments of the return series for the market indices are shown in Table 1. As reported in Harvey (1995), the emerging markets are characterized both by high expected returns and high volatility. Excess kurtosis is also important in most countries. Except for a few countries, there is also a fair degree of predictability based on past information, as indicated by the Box-Ljung statistic.

The purpose of the tests of conditional factor models is precisely to determine to what extent this predictability is explained by a dynamic factor model, in which the conditional expected return varies through time either because the factor loadings or the price of risk are timevarying, or both. We will analyze below first the results obtained for the conditional CAPM based on the world market portfolio. In this model, the underlying hypothesis is that emerging markets are perfectly integrated. In the next two specifications tested, we abandon this hy- 
pothesis and turn to a set of size sorted portfolios to test whether the local market index suffices as a factor to explain the portfolio returns. If it is the case, we will conclude to a segmentation of the markets. If other external factors along with the local market index covary significantly with the portfolio returns, we will infer that a semi-integration of the emerging markets is more likely. To assess all models, we will look not only at the J-test for overidentifying restrictions as all studies based on GMM estimation do, but also at the Sup LM stability test described in Section 2.

Let us first start with the conditional CAPM specification that makes the rather strong assumption that emerging markets are integrated with world financial markets. To estimate the conditional model in (3.4), we need to specify a set of instruments. Harvey (1991) used the following instruments: (1) a constant, (2) a January dummy, (3) lagged $r_{M t},(4)$ the return on a 90-days T-Bill minus that of a 30-days one, (5) the Moody Baa yield minus the Aaa one and (6) the dividend yield on the S\&P500 minus the 30-days T-Bill return. The instruments used were taken from the Center for Research in Security Prices (CRSP) or from the Fama bond files on CRSP. All details can be found in the original work by Harvey (1991). Harvey (1995) used the same instruments except the January dummy to test a similar model on emerging markets. ${ }^{8}$

The results are presented in Table 2 . The J-statistics testing the overidentifying restrictions (a total of 6 since we have 18 moment conditions and 12 parameters to estimate) are reported in the first column of Table 2. For all the countries, the model is not rejected at the usual $5 \%$ level based on the $\chi^{2}(6)$ distribution for the J-statistic. ${ }^{9}$ According to the Sup LM test however, there is most of the time at least one stability test rejecting the null. The two exceptions are Argentina and Korea which pass both sets of tests, even though the first country has undergone periods of economic upheaval during the sample period chosen, and regulatory reforms have affected the second. On the other hand, Brazil provides a very good example of our contention. It has one of the lowest J-statistic, but as is the case with India, the rejections with structural stability tests are numerous and strong.

The previous model considered as assets of interest the market portfolio for each of the individual countries in our sample. To proceed further, we consider a conditional CAPM using as assets for each coun-

\footnotetext{
${ }^{8}$ The sampling period for our instruments ends in 1989:05. Our estimations are therefore based on 161 observations, starting in January 1976.

${ }^{9}$ Harvey (1995) rejects the model for all countries but, as mentioned before, this test is different from ours. He does not test as such overidentifying restrictions since his model is just identified.
} 
try a set of three portfolios formed according to the capitalization value of the individual firms in the IFC databank. The market portfolio is represented by the country indices that we used as assets before. This simple test of the CAPM theory in emerging markets has to the best of our knowledge not yet been performed and appears to be the reference model one would like to build to compare results with the results obtained in the US markets both in terms of acceptance or rejection of the model and of the presence of anomalies such as the small size effect. We first start using only country-specific or local factors, then we add two US factors (the Treasury bill rate and the Standard and Poor's index) to the previous model to see if there is any additional explanatory power for these factors, which will tend to show that emerging markets are semi-integrated to the US market.

In Table 3, we report the stability results for each projection coefficient (the $\delta$ s for the market portfolio and the $\gamma \mathrm{s}$ for the size portfolio), as well as for the corresponding $\delta$ and $\gamma$ groups of coefficients and $\beta$, the covariance between each size portfolio returns and the market portfolio returns over the variance of the market portfolio returns. Since the particular specification selected assumes a constant $\beta$, the stability test is of particular economic interest because it assesses whether the risk measure of the portfolio in question has been stable or not over the sample period considered. For all the estimations, the instruments selected are a constant, the lagged market portfolio return, the dividend-price ratio calculated from the same ratio for the individual stocks included in the portfolio, and the exchange rate with the US dollar of each particular currency.

As a general assessment of the results, we can say that the p-values obtained for the J-test are surprisingly supportive of this simple CAPM model and that the model shows remarkable stability over almost all portfolios in all countries. The values estimated for $\beta$, which are reported in Table 4, are all reasonable, highly significant and in line with the CAPM prediction in four of the ten countries (Chile, Mexico, Greece, Zimbabwe). There is some evidence of a small size effect in the rest of the countries. The beta values for the small or medium firm portfolios are greater than the beta value of the high capitalization portfolio, implying higher expected returns in equilibrium than observed. In terms of p-value of the J-test, Zimbabwe gets both the lowest value of 0.21 and the highest one of 0.87 . The beta Sup LM tests in table 3 show remarkable stability. Except for a few strong rejections for small and medium size portfolios in Korea and Thailand, one cannot reject the absence of structural change in the risk measure of the portfolios. For the other parameters, we observe the same overall stability with a few exceptions, 
especially in Thailand. According to these results, one would not reject the segmentation of the emerging markets, although to be rigorous about it one should test the orthogonality of the residuals with respect to US or other world factors. We do not perform these tests, but in the next section, we add two US factors to the local market portfolio and test the semi-integration hypothesis.

Table 5 reports the estimation results while Table 6 presents the stability results for each projection coefficient (the $\delta$ s for the US Treasury bill rate, the $\gamma_{1}$ s for the $\mathrm{S} \& \mathrm{P}$ index returns, the $\gamma_{2} \mathrm{~s}$ for the size portfolio), as well as for $\beta_{1}$, the covariance between each size portfolio returns and the market portfolio returns over the variance of the market portfolio returns, and $\beta_{2}$ and $\beta_{3}$, the corresponding measures of risk for the US Treasury bill and S\&P factors.

The betas estimated for the local market portfolio are very close to the values estimated in the previous model and bear the same strong statistical significance as before, but in addition the betas for the Treasury bill factor are often significantly different from zero. The beta estimated for the S\&P factor is usually negligible in magnitude and one cannot reject most of the time the equality to zero of this parameter. The p-values of the J-test increase significantly for most portfolios in most countries, often to values greater than $90 \%$. The big difference with the previous model comes however from the stability test results. Almost no beta is now stable with respect with the instruments selected. This is consistent with Ghysels (1996) for the coefficients associated with the US factors, and understandable for the beta of the size portfolio since now we project the local market portfolio both on local information variable and on US variables. In terms of semi-integration of the emerging markets, we can conclude that even if there often seems to be a role for the US Treasury bill factor (representing the risk-free asset factor proxying possibly for consumption growth), the main source of risk in emerging markets remains the aggregate risk included in the local market portfolio.

\section{Conclusion}

In this paper, we apply tests for structural stability to emerging markets asset pricing factor models. These models have been estimated via the generalized method of moments (GMM) procedure discussed in Hansen (1982). The success of the model fit is judged on the basis of GMM-based criteria. In particular, one tests whether the overidentifying restrictions imposed by the model agree with the data. The fundamental problem is that overidentifying restriction tests are not designed to 
diagnose whether a model provides a stable time invariant relationship between the return and the information variables. For the conditional world CAPM and the conditional local and US factor model, tests for structural stability of the GMM parameter estimates show that for most countries and portfolios according to the case, although we cannot reject the model on the basis of the overidentifying restrictions criterion, the rejection of the absence of structural change is quite strong. This is quite reasonable if one considers the strong idiosyncracies, both political and economical, that have disrupted these emerging markets in comparison with world events. This rejection means that the model yields a systematic mispricing of risk factors. A much more stable relationship is found however in a simple local CAPM model for size ranked portfolios, although the small size effect appears to be present in a number of countries. It was noted that Bekaert and Harvey $(1995,1996)$ suggested models with a time-varying structure switching from a segmented to an integrated asset pricing model for emerging market. Their specification relies on explanatory variables which represent the transition. While their model accommodates some of the issues raised in our paper it also opens new questions. Indeed, their specification depends on a specific parameterization for the transition dynamics. Implicitly, it is assumed that the time instability is resolved via this model of transition. Yet, it may well be that their model of switching is misspecified, and unstable, providing a erroneous characterization of the transition dynamics. One way to find this out would be to test the structural stability of the parameters they estimated for the transition scheme. If they are found to be stable then we have satisfactorily resolved (at least empirically) the question of transition from segmented to integrated markets. However, if find that the parameters of the transition model are unstable then we do not have a good model for the emergence of emerging markets. Applying structural stability tests to the models proposed by Bekaert and Harvey is the next step on this research agenda which we leave for further work. 


\section{A APPENDIX}

In this Appendix we provide a more formal discussion of the tests for structural stability. To set the scene we first note that the models discussed in section 3 can be expressed via a generic set of moment conditions:

$$
E\left[m\left(x_{t+1}, \Theta_{o}\right)\right]=E\left[e\left(y_{t+1}, \Theta_{o}\right) \otimes Z_{t}\right]=0
$$

where $Z_{t}$ is a set of instruments $y_{t}$ a vector process containing all asset returns, factors, etc. while $\Theta_{o}$ is the parameter vector governing the pricing functions, the projection equations or conditional betas. Equations (3.6), (3.9) (3.10) and (3.11) describe the specific examples considered in the empirical section 4 . For the purpose of discussion we shall divide the parameter vector in two subvectors, namely $\Theta_{o} \equiv\left(\gamma_{o}, \delta_{o}\right)$. This division allows for cases where we are not always interested in testing the complete parameter vector $\Theta_{o}$ but only a subvector $\gamma_{o}$. We observed in section 2 that this is often done because the parameters involved in the moment conditions play very different roles. This leads to the following null hypothesis:

$$
H_{o}: \gamma_{t}=\gamma_{0} \quad \forall t \geq 1 \text { for some } \gamma_{0} \in B \subset \mathbb{R}^{p} .
$$

When no parameter $\delta_{0}$ is present, one tests the entire parameter vector; a situation referred to as testing for pure structural change. Otherwise, one tests for partial structural change. The alternative hypothesis consists of a one-time change at some point $\pi \epsilon(0,1)$. Then, with sample size $T$, the change occurs at $\pi T$ and can be formulated as:

$$
H_{1 T}(\pi): \gamma_{t}=\left\{\begin{array}{l}
\gamma_{1}(\pi) \text { for } t=1, \ldots, \pi T \\
\gamma_{2}(\pi) \text { for } t=\pi T+1, \ldots, T
\end{array}\right.
$$

for some constants $\gamma_{1}(\pi), \gamma_{2}(\pi) \epsilon B \subset \mathbb{R}^{p}$. As $\pi$ is assumed unknown or $\pi \epsilon \Pi \subset(0,1)$ a pre-specified subset Andrews (1993) proposed to compute Wald, LM and LR-like tests for all $\pi$ in $\Pi$ and consider statistics of the form $g\left(\left\{S_{T}(\pi), \pi \epsilon \Pi\right\}\right)$ where the statistic $S_{T}(\pi)$ equals $W_{T}(\pi), L M_{T}(\pi)$ or $L R_{T}(\pi)$ if Wald, $L M$ or $L R$ tests are computed. Andrews and 
Ploberger (1994) formulated a unifying framework for the choice of the function $g$ depending upon the alternatives of interest. In particular, consider

$$
g\left(\left\{S_{T}(\pi), \pi \epsilon \Pi\right\}\right)=(1+c)^{p / 2} \int_{\Pi} \exp \left[\frac{1}{2} \frac{c}{1+c} T S_{T}(\pi)\right] d J(\pi)
$$

where $J(\pi)$ is a weight function over the values of $\pi \epsilon \Pi$ and $c$ determines the direction for the power of the test. When $c \rightarrow \infty$, tests have power against distant alternatives giving greater weight to large structural changes. Such tests are denoted $\operatorname{ExpS}_{T}$. We did compute the ExpLM $_{T}$ tests (available upon request), but since they yielded results quite similar to the $\mathrm{SupS}_{T}$ tests we are about to discuss we omitted then to save space.

An alternative design for the function $g$ is of the "sup" form. It corresponds to a case where $c /(1+c)$ is equal to a constant and this constant goes to infinity. Andrews (1993) initially proposed such tests, namely:

$$
\operatorname{Sup}_{\pi \in \Pi} W_{T}(\pi) \underset{\pi \in \Pi}{\operatorname{Sup}} \operatorname{LM} M_{T}(\pi) \text { and } \underset{\pi \in \Pi}{\operatorname{Sup}} \operatorname{LR} R_{T}(\pi)
$$

Of these six test statistics we shall only consider the LM variety. There are two reasons for confining our attention to SupLM (and ExpLM) statistics. First, unlike their Wald and LR counterparts, they only require one estimation of the model over the entire sample. Second, based on Monte Carlo simulations Ghysels and Guay (1994) find that the LM statistics have, compared to the Wald and LR tests, very good power properties and show no notable size distortions.

To discuss the tests more formally, let $\hat{V}(\pi) i=1,2$ be the sample covariance matrices obtains from a standard GMM procedure with heteroskedasticity and autocorrelation consistent covariance matrix estimation [see, e.g., Hansen (1982), Gallant and White (1988), Hall (1993) or Ogaki (1993) for general discussion]. The LM statistic makes use of the full-sample GMM estimator $(\hat{\gamma}, \hat{\delta})$ and can be written as:

$$
L M_{T}(\pi)=C_{T}(\pi)^{\prime}\left(\hat{V}_{1}(\pi) \prime \pi+\hat{V}_{2}(\pi) \prime(1-\pi)\right)^{-1} C_{T}(\pi)
$$

where $C_{T}(\pi)$ is computed as

$C_{T}(\pi)=\left[I_{q}-I_{q}\right]\left[\begin{array}{cc}\pi^{-1}\left(\hat{M}_{1}^{\prime} \hat{S}_{1}^{-1} \hat{M}_{1}\right)^{-1} \hat{M}_{1}^{\prime} \hat{S}_{1}^{-1} & 0 \\ 0 & (1-\pi)^{-1}\left(\hat{M}_{2}^{\prime} \hat{S}_{2}^{-1} \hat{M}_{2}\right)^{-1} \hat{S}_{2}^{-1}\end{array}\right] \sqrt{T} \bar{m}_{T}(\hat{\gamma}, \hat{\delta}, \pi)$ 
where $\bar{m}_{T}(\hat{\gamma}, \tilde{\delta}, \pi)$ is the set of moment conditions $m\left(x_{t+1}, \gamma, \delta\right) \epsilon R^{q}$ stacked according to the sample split at $\pi$ evaluated at the full sample estimates $\hat{\gamma}$ and $\hat{\delta}$ :

$$
\bar{m}_{T}(\hat{\gamma}, \hat{\delta}, \pi)=\frac{1}{T} \sum_{t=1}^{\pi T}\left[\begin{array}{c}
m\left(x_{t+1}, \hat{\gamma}, \hat{\delta}\right) \\
0
\end{array}\right]+\frac{1}{T} \sum_{t=T \pi+1}^{T}\left[\begin{array}{c}
0 \\
m\left(x_{t+1}, \hat{\gamma}, \hat{\delta}\right)
\end{array}\right]
$$

while $\hat{M}_{i}=\hat{M}_{i}(\pi)$ is the score function of the sample moment conditions $m\left(x_{t}, \gamma_{1}, \delta\right)$ with respect to $\gamma_{i}$ for $i=1,2$. Finally, $\hat{S}_{i}=\hat{S}_{i}(\pi)$ is the heteroskedasticity and autocorrelation consistent covariance estimator of the sample moment conditions for $i=1,2$. In our case we simplified the computations, as is typically done by using, the full sample estimates $\hat{M}_{i}(\pi)=\hat{M}$ and $\hat{S}_{i}(\pi)=\hat{S}$. 


\section{References}

[1] Andrews, D.W.K. (1993), "Tests for Parameter Instability and Structural Change with Unknown Change Point," Econometrica 61, 821-856.

[2] Andrews, D.W.K. and R. Fair (1988), "Inference in Econometric Models with Structural Change," Review of Economic Studies 55, 615-640.

[3] Bekaert, G. and C.R. Harvey (1995), "Time-varying world market integration", Journal of Finance 50, 403-444.

[4] Bekaert, G. and C.R. Harvey (1996), "Emerging Equity Market Volatility", Journal of Financial Economics (forthcoming).

[5] Dufour, J.M., E. Ghysels and A. Hall (1994) "Generalized Predictive Tests for Structural Change", International Economic Review 35, 199-229.

[6] Ferson, W.E.,(1985), "Changes in expected risk premiums and security risk measures." Proceedings of the European Finance Association.

[7] Ferson, W.E. and C.R. Harvey, (1991), "The Variation of Economic Risk Premiums," Journal of Political Economy 99, 385-415.

[8] Ferson, W.E. and C.R. Harvey, (1995), "The risk and predictability of international equity returns," Review of Financial Studies 6, 527566.

[9] Ferson, W.E. and R.A. Korajczyk (1995), "Do arbitrage pricing models explain the predictability of stock returns?", Journal of Business 68, 309-349.

[10] Gallant, A.R. and H. White (1988), "A Unified Theory of Estimation and Inference for Nonlinear Dynamic Models," Basil Blackwell, New-York.

[11] Ghysels, E. (1996), "On Stable Factors in the Pricing of Risk," Discussion Paper, Cirano and C.R.D.E., Université de Montréal. 
[12] Ghysels, E. and A. Hall (1990a), "A Test for Structural Stability of Euler Conditions Parameters Estimated via the Generalized Method of Moments Estimator," International Economic Review $31,355-364$.

[13] Ghysels, E. and A. Hall (1990b), "Are Consumption-Based Intertemporal Capital Asset Pricing Models Structural?," Journal of Econometrics 45, 121-139.

[14] Ghysels, E., A. Guay and A. Hall (1994), "Predictive Tests for Structural Change with Unknown Breakpoint" Journal of Econometrics (forthcoming).

[15] Hansen, L.P., (1982), "Large Sample Properties of Generalized Method of Moments Estimators," Econometrica 50, 1029-1054.

[16] Hansen, L.P. and R. Jagannathan (1991), "Implications of security market data for models of dynamic economies." Journal of Political Economy 99, 225-262.

[17] Harvey, C.R. (1991), "The World Price of Covariance Risk," Journal of Finance XLVI, 111-157.

[18] Harvey, C.R. (1995), "Predictable risk and returns in emerging markets", Review of Financial Studies 8, 773-816. 
Table 1: Sample Moments of Return Series.

\begin{tabular}{|c|c|c|c|c|c|c|c|c|c|c|}
\hline & Argentina & Brazil & Chile & Mexico & India & Korea & Thailand & Greece & Jordan & Zimbabwe \\
\hline Mean & 67.8743 & 22.0970 & 36.6650 & 30.3904 & 20.2028 & 21.2641 & 22.3295 & 7.4654 & 10.7468 & 7.7733 \\
\hline Std. Dev. & 103.9108 & 60.2414 & 39.5773 & 44.5639 & 27.2278 & 32.3377 & 25.7566 & 36.2207 & 17.8933 & 34.1728 \\
\hline Skewness & 1.9470 & 0.5151 & 0.9244 & -0.8197 & 0.6574 & 0.9835 & -0.0955 & 1.8198 & 0.3688 & .02822 \\
\hline Kurtosis & 7.1250 & 0.9793 & 3.0661 & 3.6287 & 2.1912 & 1.9125 & 3.2061 & 7.2264 & 0.1873 & 1.8440 \\
\hline$\rho_{1}$ & 0.0537 & 0.0287 & 0.1687 & 0.2475 & 0.0789 & -0.0012 & 0.1142 & 0.1322 & 0.0003 & 0.1380 \\
\hline$\rho_{2}$ & 0.0660 & -0.0377 & 0.2604 & -0.0739 & -0.0994 & 0.0820 & 0.1487 & 0.1789 & 0.0244 & 0.1539 \\
\hline$\rho_{3}$ & 0.1180 & -0.0362 & -0.0117 & -0.0391 & -0.0323 & 0.0163 & 0.0052 & 0.0282 & 0.1801 & .02447 \\
\hline$\rho_{4}$ & -0.0503 & -0.0670 & -0.0330 & 0.0352 & -0.1037 & -0.0155 & -0.1137 & -0.0572 & 0.0036 & 0.1675 \\
\hline$\rho_{5}$ & -0.0502 & -0.0411 & 0.0052 & 0.1223 & 0.0130 & 0.0501 & -0.0172 & 0.0388 & -0.0733 & 0.1109 \\
\hline $\begin{array}{c}\text { Box-Ljung } \\
\text { Statistic }\end{array}$ & 8.0539 & 7.3939 & 37.2628 & 22.7292 & 16.8850 & 5.8281 & 18.0510 & 24.2990 & 18.3117 & 41.3448 \\
\hline P-Value & 0.6236 & 0.6878 & 0.00005 & 0.0118 & 0.0769 & 0.8295 & 0.0541 & 0.0068 & 0.0499 & 0.00001 \\
\hline
\end{tabular}




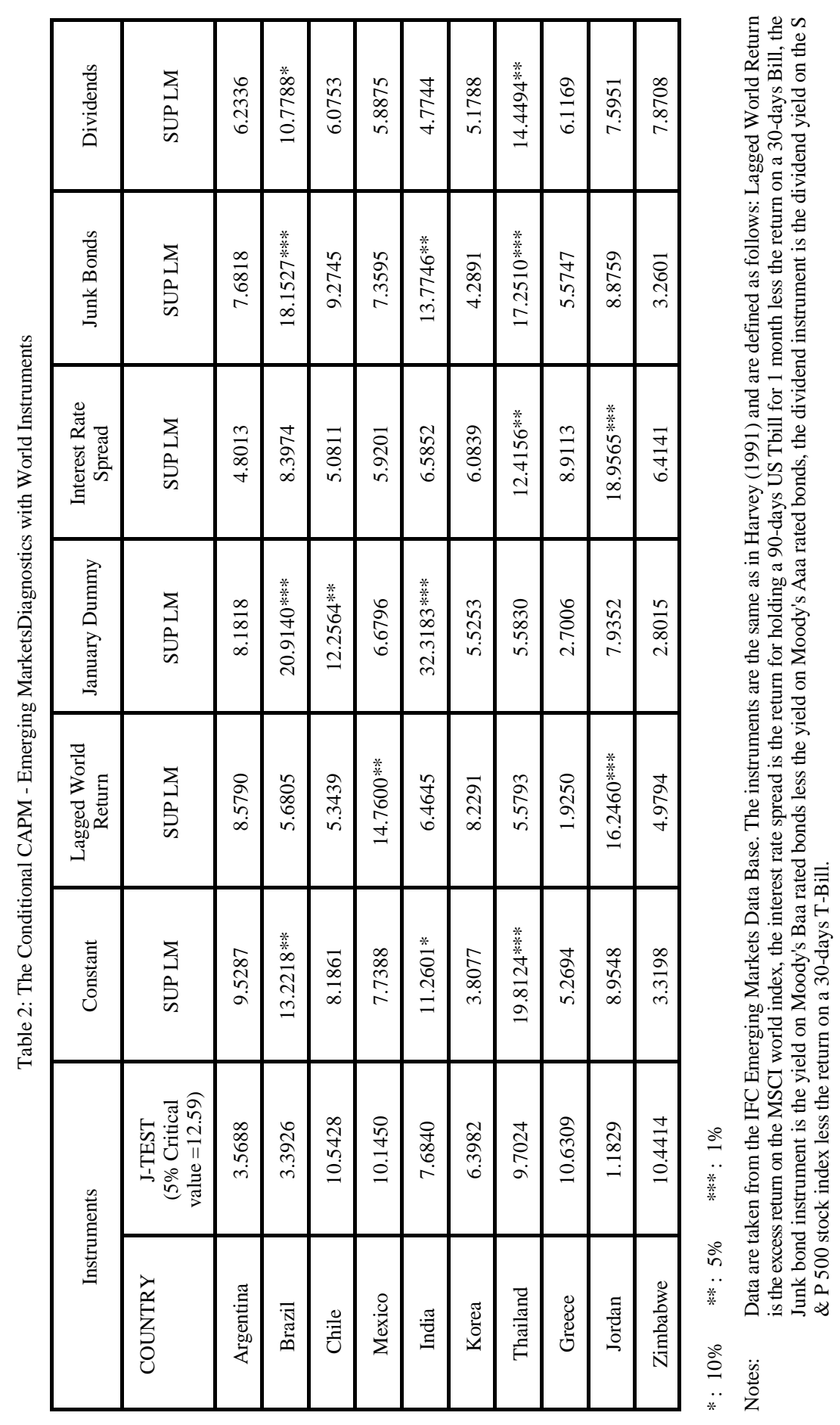


Table 3: Sized-Sorted Portfolios and Local Conditional CAPM. Sup LM Statistics

\begin{tabular}{|c|c|c|c|c|c|c|c|c|c|c|c|c|}
\hline & \multicolumn{3}{|c|}{ Argentina } & \multicolumn{3}{|c|}{ Brazil } & \multicolumn{3}{|c|}{ Chile } & \multicolumn{3}{|c|}{ Korea } \\
\hline & Low & Medium & High & Low & Medium & High & Low & Medium & High & Low & Medium & High \\
\hline $\begin{array}{c}\text { J-Test } \\
(\rho- \\
\text { value }) \\
\end{array}$ & $\begin{array}{c}2.8292 \\
(0.4187)\end{array}$ & $\begin{array}{c}3.3825 \\
(0.3363)\end{array}$ & $\begin{array}{c}1.0364 \\
(0.7924)\end{array}$ & $\begin{array}{c}1.5552 \\
(0.6696)\end{array}$ & $\begin{array}{c}3.6957 \\
(0.2963)\end{array}$ & $\begin{array}{c}2.4627 \\
(0.4821)\end{array}$ & $\begin{array}{c}2.7651 \\
(0.4293)\end{array}$ & $\begin{array}{c}5.1104 \\
(0.1639)\end{array}$ & $\begin{array}{c}0.9606 \\
(0.8108)\end{array}$ & $\begin{array}{c}1.7197 \\
(0.6326)\end{array}$ & $\begin{array}{c}2.1606 \\
(0.5398)\end{array}$ & $\begin{array}{c}4.1450 \\
(0.2462)\end{array}$ \\
\hline$\delta_{\mathrm{ALL}}$ & 9.0267 & 6.3565 & 4.0856 & 3.6137 & 9.7680 & 10.008 & 6.2101 & 9.6974 & 9.3647 & 7.2878 & 13.3701 & 3.0729 \\
\hline$\delta_{1}$ & 2.5409 & 3.4513 & 1.6820 & 1.4656 & 2.5445 & $8.0050 *$ & 4.7136 & 2.8047 & 2.1945 & 0.8402 & 2.1419 & 1.5670 \\
\hline$\delta_{2}$ & 5.5693 & 2.3374 & 1.5157 & 1.3854 & 1.9506 & 4.4374 & 1.6839 & $7.5225 *$ & $8.2684 *$ & 5.1781 & 3.1006 & 1.7717 \\
\hline$\delta_{3}$ & 3.3084 & 3.5896 & 1.8058 & 0.5050 & $7.7186 *$ & 2.9454 & 4.9925 & 5.5509 & 2.2218 & 2.4261 & 6.8347 & 1.6697 \\
\hline$\delta_{4}$ & 0.2881 & 0.3826 & 1.0552 & 3.1143 & 3.2208 & 1.5463 & 6.1003 & 3.6770 & 4.9170 & 1.0917 & 1.9449 & 1.7542 \\
\hline$\gamma_{\mathrm{ALL}}$ & 10.8479 & 5.7808 & 3.5979 & 10.1144 & 4.8671 & 7.0362 & 8.1169 & $14.4437 *$ & 7.5934 & 11.4990 & 5.1826 & 4.4512 \\
\hline$\gamma_{1}$ & 1.8374 & 3.0444 & 1.0697 & 4.1029 & 0.7537 & 5.4768 & 3.8729 & 2.1324 & 3.8534 & 3.0013 & 2.7003 & 1.2539 \\
\hline$\gamma_{2}$ & $7.5742 *$ & 2.0609 & 1.3916 & 5.7359 & 2.1763 & 5.3890 & 1.0311 & $8.4925 *$ & 4.2528 & 2.1148 & 1.8471 & 2.8065 \\
\hline$\gamma_{3}$ & 3.5264 & 3.4179 & 1.3430 & 5.3639 & 0.9138 & 1.3858 & 4.0146 & 4.0291 & 1.7654 & 1.3136 & 3.9031 & 1.5019 \\
\hline$\gamma_{4}$ & 0.1472 & 0.1428 & 1.0158 & 2.3121 & 2.7279 & 3.1847 & 5.4686 & 3.1558 & 5.3894 & 1.7570 & 2.9657 & 1.3425 \\
\hline$\beta$ & 2.2243 & 4.3984 & 3.7517 & 4.9353 & 2.1323 & 4.4162 & 0.9354 & 2.3069 & 1.6992 & 1.6040 & $12.79 * * *$ & 4.9797 \\
\hline
\end{tabular}

*: $\quad 10 \%$

**: $\quad 5 \%$

$* * *: \quad 1 \%$

Notes: $\quad$ The columns "Low", "Medium" and "High" reflect size classifications for each country. The $\delta, \gamma$ and $\beta$ parameter (vectors) are defined by equation (2.21). The index "ALL" corresponds to joint tests for the entire vector while index $i=1,2,3,4$ reflect individual coefficient tests. The $\delta$ coefficients represent projections for the market portfolio and $\gamma$ for the size portfolio. The four instruments are local ones: a constant, lagged market returns, dividend-price ratio and exchange rate (local currency / US\$). 
Table 3 (continued): Sized-Sorted Portfolios and Local Conditional CAPM. Sup LM Statistics

\begin{tabular}{|c|c|c|c|c|c|c|c|c|c|}
\hline & \multicolumn{3}{|c|}{ Mexico } & \multicolumn{3}{|c|}{ India } & \multicolumn{3}{|c|}{ Thailand } \\
\hline & Low & Medium & High & Low & Medium & High & Low & Medium & High \\
\hline $\begin{array}{c}\text { J-Test } \\
(\rho- \\
\text { value }) \\
\end{array}$ & $\begin{array}{c}2.8348 \\
(0.4178)\end{array}$ & $\begin{array}{c}2.0242 \\
(0.5674)\end{array}$ & $\begin{array}{c}4.3164 \\
(0.2293)\end{array}$ & $\begin{array}{c}4.1218 \\
(0.2486)\end{array}$ & $\begin{array}{c}1.2539 \\
(0.7401)\end{array}$ & $\begin{array}{c}2.4898 \\
(0.4771)\end{array}$ & $\begin{array}{c}2.4393 \\
(0.4864)\end{array}$ & $\begin{array}{c}4.0717 \\
(0.2538)\end{array}$ & $\begin{array}{c}3.2135 \\
(0.3599)\end{array}$ \\
\hline$\delta_{\mathrm{ALL}}$ & $14.3788 *$ & 4.4288 & 6.7121 & 5.8186 & 8.7227 & 7.2795 & 14.3023 & 12.5514 & $\begin{array}{c}16.4528 \\
* *\end{array}$ \\
\hline$\delta_{1}$ & 4.1387 & 1.1340 & 1.2606 & 1.4963 & 1.5098 & 3.8475 & $9.6918 * *$ & 5.4571 & 1.9999 \\
\hline$\delta_{2}$ & 6.6964 & 2.0458 & 3.3015 & 1.7787 & 1.9474 & 4.2260 & 4.4048 & 6.5898 & $8.1595 *$ \\
\hline$\delta_{3}$ & 3.4565 & 2.4758 & 4.2435 & 5.0162 & 5.5713 & 3.4758 & 1.8408 & 2.0489 & 3.0859 \\
\hline$\delta_{4}$ & $10.8848 * *$ & 0.6630 & 1.1039 & 1.0783 & 1.2880 & 1.5247 & $10.1168 * *$ & 6.0409 & 2.5798 \\
\hline$\gamma_{\mathrm{ALL}}$ & 10.3581 & 7.2005 & 9.4566 & 6.3635 & 9.4542 & 8.3584 & $18.1198 * *$ & 13.4699 & $14.9622 *$ \\
\hline$\gamma_{1}$ & 3.9064 & 2.2444 & 2.3404 & 1.1914 & 2.9281 & 4.6866 & $10.5747 * *$ & 6.0444 & 3.0913 \\
\hline$\gamma_{2}$ & 2.5708 & 3.2791 & 3.4830 & 2.3221 & 1.5702 & 4.7462 & 5.4134 & 4.7838 & $8.1678 *$ \\
\hline$\gamma_{3}$ & 4.4469 & 3.7370 & $7.4219 *$ & 3.8847 & 3.9989 & 3.8582 & 1.9871 & 5.3298 & 2.5232 \\
\hline$\gamma_{4}$ & 3.9667 & 0.9312 & 0.6184 & 1.1630 & 1.9740 & 2.1609 & $11.3963 * *$ & 6.8089 & 2.7106 \\
\hline$\beta$ & 1.7661 & 3.1538 & 5.9439 & 6.0892 & 2.0503 & 6.4365 & $14.0362 * * *$ & $\begin{array}{c}12.9839 \\
* * *\end{array}$ & 1.1867 \\
\hline
\end{tabular}

*: $\quad 10 \%$

$* *: \quad 5 \%$

***: $\quad 1 \%$

Notes: $\quad$ The columns "Low", "Medium" and "High" reflect size classifications for each country. The $\delta, \gamma$ and $\beta$ parameter (vectors) are defined by equation (2.21). The index "ALL" corresponds to joint tests for the entire vector while index $i=1,2,3,4$ reflect individual coefficient tests. The $\delta$ coefficients represent projections for the market portfolio and $\gamma$ for the size portfolio. The four instruments are local ones: a constant, lagged market returns, dividend-price ratio and exchange rate (local currency / US\$). 
Table 3 (continued): Sized-Sorted Portfolios and Local Conditional CAPM. Sup LM Statistics

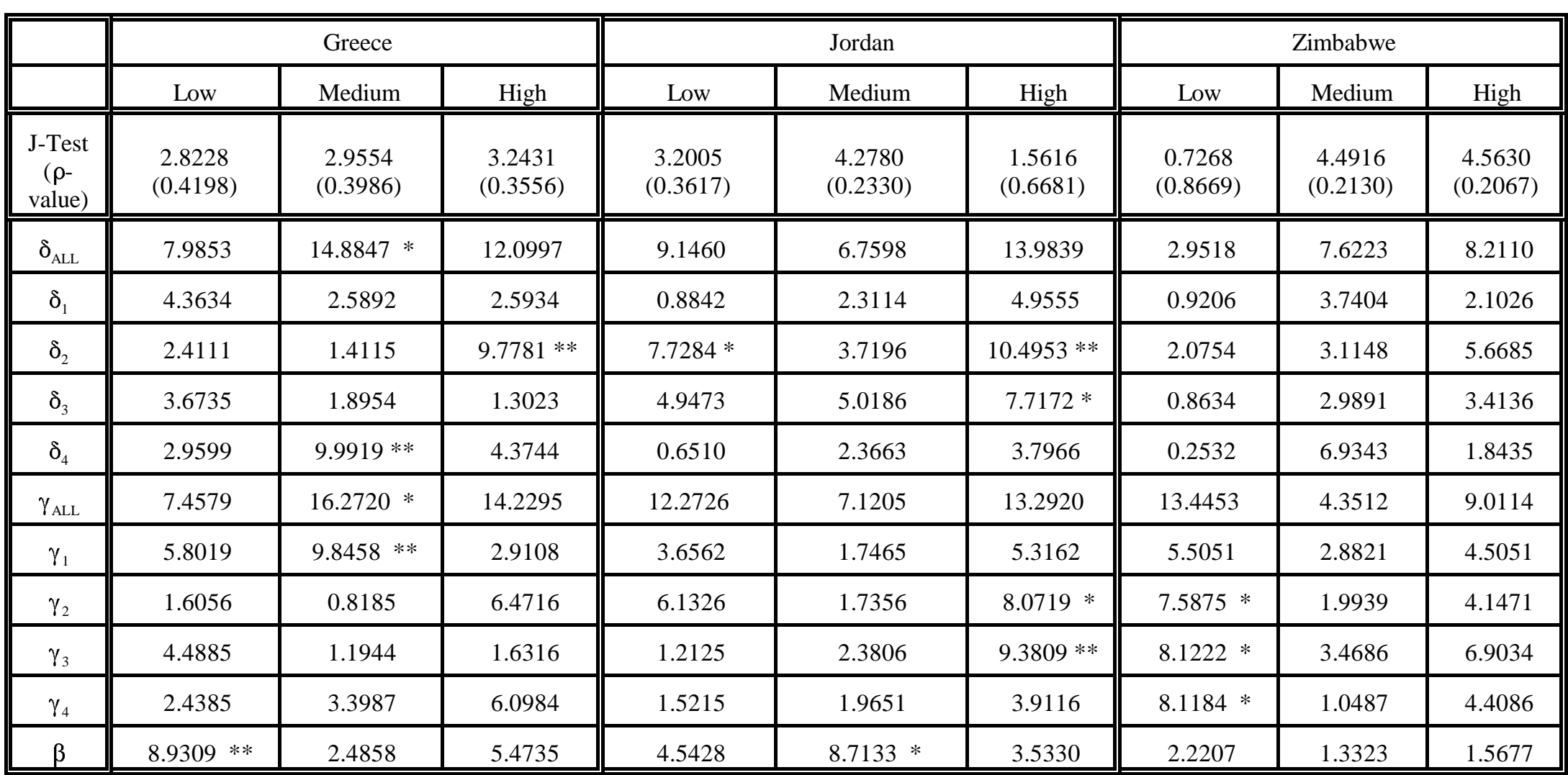

*: $10 \% \quad * *: \quad 5 \% \quad * * *: 1 \%$

Notes: The columns "Low", "Medium" and "High" reflect size classifications for each country. The $\delta, \gamma$ and $\beta$ parameter (vectors) are defined by equation (2.21). The index "ALL" corresponds to joint tests for the entire vector while index $\mathrm{i}=1,2,3,4$ reflect individual coefficient tests. The $\delta$ coefficients represent projections for the market portfolio and $\gamma$ for the size portfolio. The four instruments are local ones: a constant, lagged market returns, dividend-price ratio and exchange rate (local currency / US\$). 


\begin{tabular}{|c|c|c|c|c|}
\hline \multicolumn{5}{|c|}{$\begin{array}{l}\text { Table 4: Local Factor only - Emerging Markets } \\
\text { Beta Estimates } \\
\end{array}$} \\
\hline & & Low & Medium & High \\
\hline \multirow{3}{*}{ Argentina } & Mean Excess Return & 0.0863 & 0.0742 & 0.0733 \\
\hline & Estimates & 0.9931 & 1.0096 & 0.9868 \\
\hline & $t$-statistics & $17.9505 * * *$ & $13.8476 * * *$ & $18.0052 * * *$ \\
\hline \multirow{3}{*}{ Brazil } & Mean Excess Return & 0.0214 & 0.0413 & 0.0305 \\
\hline & Estimates & 0.8043 & 0.8692 & 0.8334 \\
\hline & $t$-statistics & $10.2836 * * *$ & $10.3986 * * *$ & $15.0118 * * *$ \\
\hline \multirow{3}{*}{ Chile } & Mean Excess Return & 0.0183 & 0.0280 & 0.0376 \\
\hline & Estimates & 0.8458 & 0.9569 & 1.0488 \\
\hline & $t$-statistics & $14.0004 * * *$ & $22.5047 * * *$ & $30.5322 * * *$ \\
\hline \multirow{3}{*}{ Korea } & Mean Excess Return & 0.0111 & 0.0188 & 0.0177 \\
\hline & Estimates & 0.9555 & 0.8565 & 1.0246 \\
\hline & $t$-statistics & $14.5874 * * *$ & $25.3095 * * *$ & $52.2570 * * *$ \\
\hline \multirow{3}{*}{ Mexico } & Mean Excess Return & 0.0262 & 0.0281 & 0.0281 \\
\hline & Estimates & 0.7796 & 0.9066 & 1.0440 \\
\hline & $t$-statistics & $10.4039 * * *$ & $22.2280 * * *$ & $23.7472 * * *$ \\
\hline \multirow{3}{*}{ India } & Mean Excess Return & 0.0068 & 0.0110 & 0.0156 \\
\hline & Estimates & 0.9408 & 0.8393 & 1.0356 \\
\hline & $t$-statistics & $18.0429 * * *$ & $22.5687 * * *$ & $35.7327 * * *$ \\
\hline \multirow{3}{*}{ Thailand } & Mean Excess Return & 0.0042 & 0.0189 & 0.0154 \\
\hline & Estimates & 1.0516 & 1.0847 & 1.0012 \\
\hline & $t$-statistics & $12.6958 * * *$ & $23.9927 * * *$ & $23.3806 * * *$ \\
\hline \multirow{3}{*}{ Greece } & Mean Excess Return & -0.0024 & 0.0122 & 0.0043 \\
\hline & Estimates & 0.5324 & 0.7060 & 1.0853 \\
\hline & $t$-statistics & $8.7231 * * *$ & $14.7976 * * *$ & $18.0748 * * *$ \\
\hline \multirow{3}{*}{ Jordan } & Mean Excess Return & -0.0026 & 0.0088 & 0.0071 \\
\hline & Estimates & 0.7126 & 0.6752 & 1.0616 \\
\hline & $t$-statistics & $5.7606 * * *$ & $5.4148 * * *$ & $32.7147 * * *$ \\
\hline \multirow{3}{*}{ Zimbabwe } & Mean Excess Return & 0.0018 & 0.0061 & 0.0168 \\
\hline & Estimates & 0.8061 & 0.9093 & 1.0665 \\
\hline & $t$-statistics & $9.6301 * * *$ & $11.7193 * * *$ & $28.9154 * * *$ \\
\hline
\end{tabular}




\begin{tabular}{|c|c|c|c|c|c|c|c|c|c|c|}
\hline \multicolumn{11}{|c|}{$\begin{array}{r}\text { Table 5: Stable Factors in the Conditional APT- Emerging Market } \\
\text { Beta Estimates }\end{array}$} \\
\hline & & \multicolumn{3}{|c|}{ Argentina } & \multicolumn{3}{|c|}{ Brazil } & \multicolumn{3}{|c|}{ Chile } \\
\hline & & Low & Medium & High & Low & Medium & High & Low & Medium & High \\
\hline \multirow{2}{*}{$\beta_{1}$} & Estimates & 1.0551 & 0.9896 & 0.9986 & 0.7652 & 1.0558 & 0.9651 & 0.7749 & 0.9195 & 1.0592 \\
\hline & $t$-statistics & $16.52 * *$ & $22.49 * *$ & $21.01 * * *$ & $10.01 * * *$ & $12.43 * * *$ & $16.10 * * *$ & $19.43 * * *$ & $33.40 * * *$ & $51.06 * * *$ \\
\hline \multirow{2}{*}{$\boldsymbol{\beta}_{2}$} & Estimates & -1.9747 & -2.5964 & 3.2061 & 2.0188 & 20.2229 & 2.5293 & 3.6334 & 0.9874 & -0.7825 \\
\hline & $t$-statistics & -0.55 & -0.79 & 0.92 & 0.55 & $3.35 * * *$ & $1.94 * *$ & $2.64 * * *$ & 1.25 & -0.88 \\
\hline \multirow{2}{*}{$\beta_{3}$} & Estimates & 0.1337 & -0.0514 & 0.2286 & 0.2612 & -0.0195 & -0.0166 & 0.3507 & -0.0273 & -0.2813 \\
\hline & $t$-statistics & 0.88 & -0.29 & $1.46 *$ & 1.20 & -0.08 & -0.16 & $3.82 * * *$ & -0.39 & $-2.57 * * *$ \\
\hline & & \multicolumn{3}{|c|}{ Korea } & \multicolumn{3}{|c|}{ Mexico } & \multicolumn{3}{|c|}{ India } \\
\hline & & Low & Medium & High & Low & Medium & High & Low & Medium & High \\
\hline \multirow{2}{*}{$\beta_{1}$} & Estimates & 0.9481 & 0.8391 & 0.9960 & 0.8233 & 0.8730 & 1.0413 & 0.8782 & 0.8279 & 1.0777 \\
\hline & $t$-statistics & $14.31 * * *$ & $25.27 * * *$ & $49.42 * * *$ & $16.08 * * *$ & $21.64 * * *$ & $31.50 * * *$ & $21.40 * * *$ & $18.80 * * *$ & $48.42 * * *$ \\
\hline \multirow{2}{*}{$\boldsymbol{\beta}_{2}$} & Estimates & -4.5298 & 2.1364 & 0.6433 & 0.1975 & 2.6562 & -1.1247 & -2.1121 & -1.1343 & 0.3190 \\
\hline & $t$-statistics & $-2.88 * * *$ & $3.23 * * *$ & 1.09 & 0.10 & $1.79 * *$ & -1.11 & $-3.47 * * *$ & $-1.91 * *$ & 0.79 \\
\hline \multirow{2}{*}{$\beta_{3}$} & Estimates & -0.0166 & -0.0234 & -0.0306 & -0.0951 & 0.1025 & -0.2419 & 0.0433 & 0.0554 & -0.0662 \\
\hline & $t$-statistics & -0.17 & -0.35 & -0.66 & -0.78 & 0.92 & $-2.76 * * *$ & 0.91 & $1.81 * *$ & $-2.41 * * *$ \\
\hline
\end{tabular}

\footnotetext{
*: $10 \% \quad * *: 5 \% \quad * *: 1 \%$
} 


\begin{tabular}{|c|c|c|c|c|c|c|c|c|c|c|}
\hline \multicolumn{11}{|c|}{$\begin{array}{l}\text { Table } 5 \text { (continued): Stable Factors in the Conditional APT- Emerging Markets (with Tbills, SP500 and Local Index as Factors) } \\
\text { Beta Estimates }\end{array}$} \\
\hline & & \multicolumn{3}{|c|}{ Thailand } & \multicolumn{3}{|c|}{ Greece } & \multicolumn{3}{|c|}{ Jordan } \\
\hline & & Low & Medium & High & Low & Medium & High & Low & Medium & High \\
\hline \multirow{2}{*}{$\beta_{1}$} & Estimates & -0.2717 & -0.0851 & 0.9784 & 0.5052 & 0.6616 & 0.9739 & 30.4913 & 0.5571 & 1.0487 \\
\hline & $t$-statistics & $-1.74 * *$ & -0.36 & $50.67 * * *$ & $10.43 * * *$ & $10.49 * * *$ & $34.96 * * *$ & $5.47 * * *$ & $9.09 * * *$ & $51.72 * * *$ \\
\hline \multirow{2}{*}{$\boldsymbol{\beta}_{2}$} & Estimates & -6.4005 & -3.7151 & 0.8744 & 1.0244 & -2.1384 & 1.0986 & -30.4430 & 0.6329 & -0.2122 \\
\hline & $t$-statistics & $-1.66 * *$ & -0.68 & $2.45 * * *$ & 1.07 & $-2.05 * *$ & $1.71 * *$ & -0.47 & 0.86 & -0.75 \\
\hline \multirow{2}{*}{$\beta_{3}$} & Estimates & 0.0698 & -0.1303 & -0.0198 & 0.0540 & 0.0143 & -0.0166 & -4.8421 & 0.3172 & -0.0556 \\
\hline & $t$-statistics & 0.27 & -0.42 & -0.86 & 0.89 & 0.22 & -0.40 & -0.82 & $5.05 * * *$ & $-2.94 * * *$ \\
\hline & & \multicolumn{3}{|c|}{ Zimbabwe } & & & & & & \\
\hline & & Low & Medium & High & & & & & & \\
\hline \multirow{2}{*}{$\beta_{1}$} & Estimates & 0.7122 & 0.8563 & 1.0252 & & & & & & \\
\hline & $t$-statistics & $8.85 * * *$ & $10.10 * * *$ & $26.82 * * *$ & & & & & & \\
\hline \multirow{2}{*}{$\boldsymbol{\beta}_{2}$} & Estimates & -0.2225 & -0.9877 & -0.3131 & & & & & & \\
\hline & $t$-statistics & -0.15 & -0.59 & -0.29 & & & & & & \\
\hline \multirow{2}{*}{$\beta_{3}$} & Estimates & -0.2722 & -0.1477 & 0.1921 & & & & & & \\
\hline & $t$-statistics & $-1.75 * *$ & $-1.61 *$ & $3.45 * * *$ & & & & & & \\
\hline
\end{tabular}

\footnotetext{
*: $10 \% \quad * *: 5 \% \quad * * *: 1 \%$
} 
Table 6: Stable Factors in the Conditional APT - Emerging Markets. With Tbills, SP500 and Local Index as Factors. Sup LM Statistics

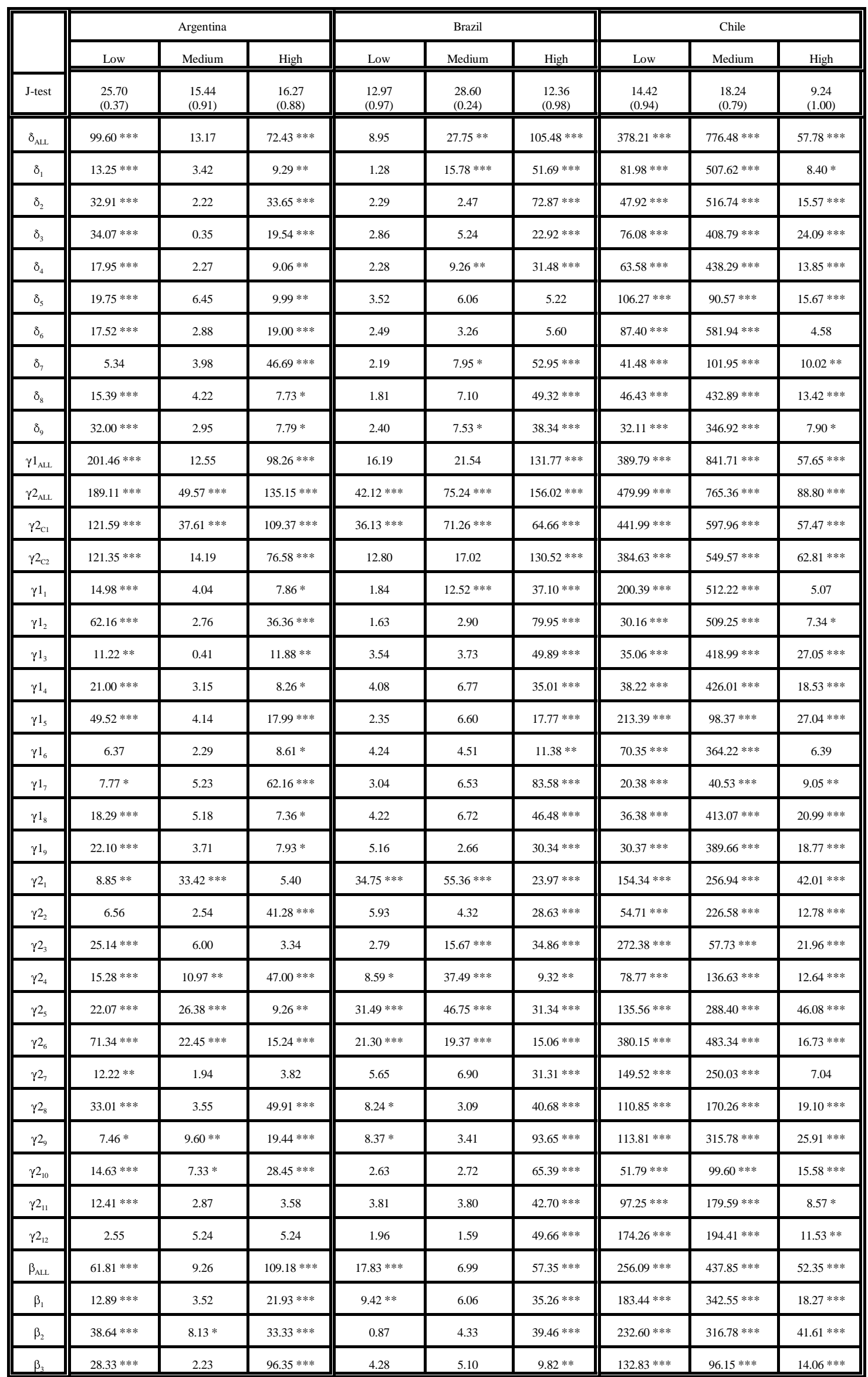

$*: 10 \% \quad * *: 5 \% \quad * * *: 1 \%$ 
Table 6 (continued): Stable Factors in the Conditional APT - Emerging Markets. With Tbills, SP500 and Local Index as Factors. Sup LM Statistics.

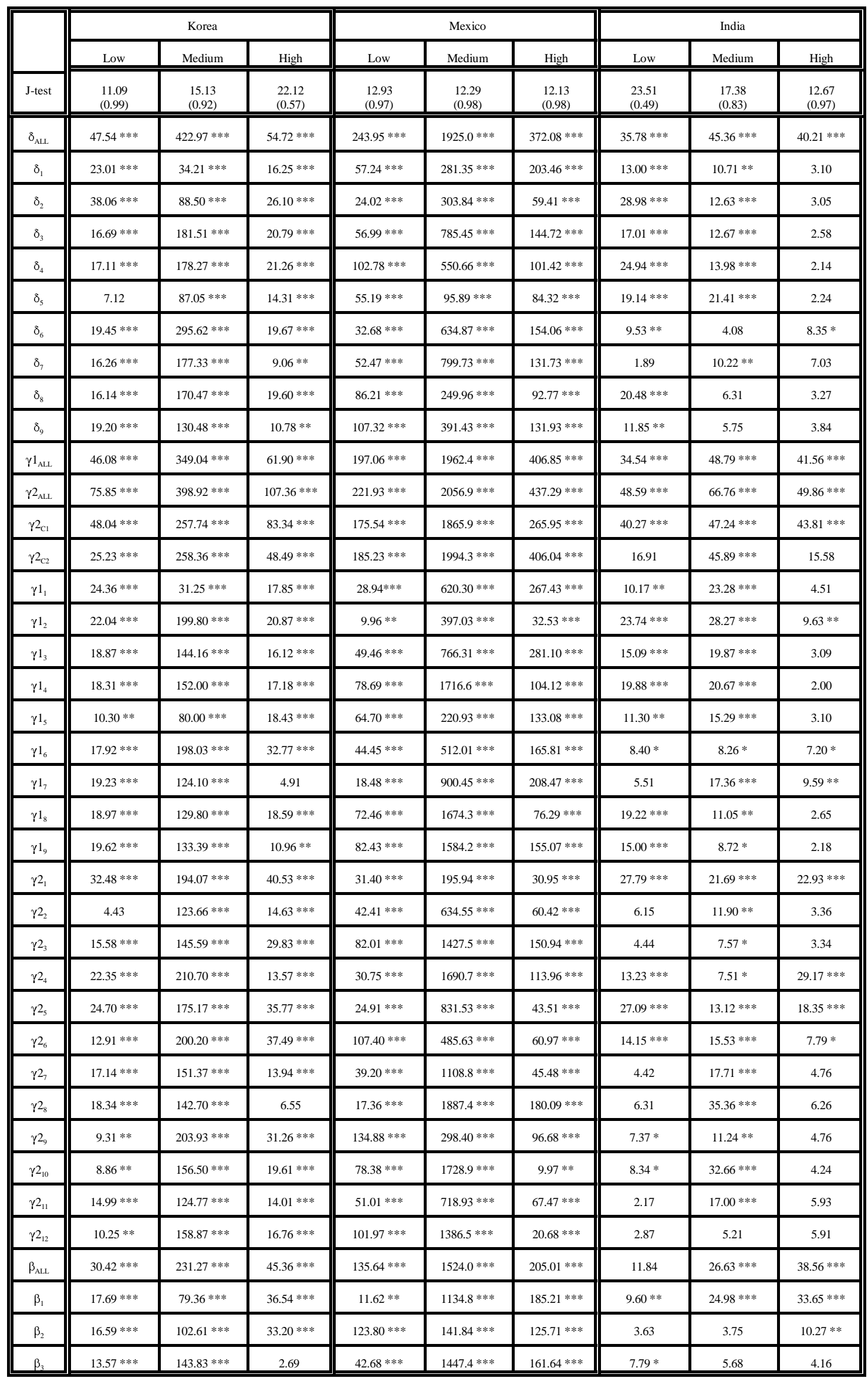

$*: 10 \% \quad * *: 5 \% \quad * * *: 1 \%$ 
Table 6 (continued): Stable Factors in the Conditional APT - Emerging Markets. With Tbills, SP500 and Local Index as Factors. Sup LM Statistics.

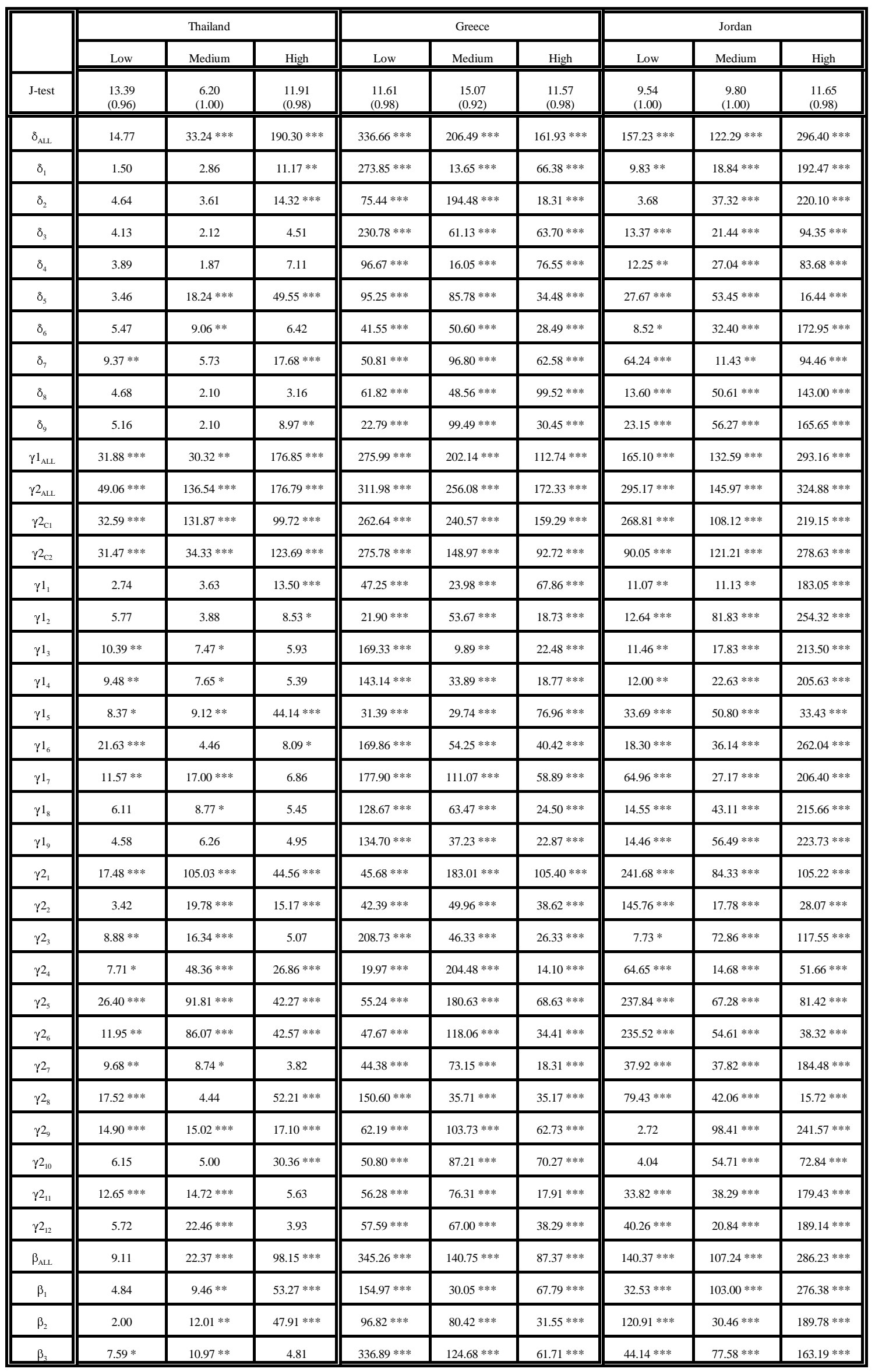

$*: 10 \% \quad * *: 5 \% \quad * * *: 1 \%$ 
Table 6 (continued): Stable Factors in the Conditional APT - Emerging Markets. With Tbills, SP500 and Local Index as Factors. Sup LM Statistics.

\begin{tabular}{|c|c|c|c|c|c|c|c|c|c|}
\hline & \multicolumn{3}{|c|}{ Zimbabwe } & \multirow[b]{2}{*}{ Low } & \multirow[b]{2}{*}{ Medium } & \multirow[b]{2}{*}{ High } & \multirow[b]{2}{*}{ Low } & \multirow[b]{2}{*}{ Medium } & \multirow[b]{2}{*}{ High } \\
\hline & Low & Medium & High & & & & & & \\
\hline J-test & $\begin{array}{r}15.24 \\
(0.91) \\
\end{array}$ & $\begin{array}{r}13.61 \\
(0.95) \\
\end{array}$ & $\begin{array}{l}21.04 \\
(0.64) \\
\end{array}$ & & & & & & \\
\hline$\delta_{\mathrm{ALL}}$ & 22.67 & $100.07 * * *$ & $36.47 * * *$ & & & & & & \\
\hline$\delta_{1}$ & 3.14 & $26.61 * * *$ & $7.19 *$ & & & & & & \\
\hline$\delta_{2}$ & $8.75 *$ & $15.81 * * *$ & $12.62 * * *$ & & & & & & \\
\hline$\delta_{3}$ & 5.56 & $40.97 * * *$ & $18.99 * * *$ & & & & & & \\
\hline$\delta_{4}$ & $10.33 * *$ & $49.64 * * *$ & $24.78 * * *$ & & & & & & \\
\hline$\delta_{5}$ & $16.40 * * *$ & $39.05 * * *$ & $17.54 * * *$ & & & & & & \\
\hline$\delta_{6}$ & 5.99 & $25.72 * * *$ & 2.12 & & & & & & \\
\hline$\delta_{7}$ & 2.84 & $41.87 * * *$ & 2.25 & & & & & & \\
\hline$\delta_{8}$ & $8.85 *$ & $20.61 * * *$ & $23.47 * * *$ & & & & & & \\
\hline$\delta_{9}$ & 6.24 & $13.58 * * *$ & $15.19 * * *$ & & & & & & \\
\hline$\gamma 1_{\mathrm{ALL}}$ & $32.32 * *$ & $109.89 * * *$ & $35.51 * * *$ & & & & & & \\
\hline$\gamma 2_{\text {ALL }}$ & $28.26 *$ & $121.38 * * *$ & $58.86 * * * *$ & & & & & & \\
\hline$\gamma 2_{\mathrm{cl}}$ & $26.00 * * *$ & $91.28 * * *$ & $42.03 * * *$ & & & & & & \\
\hline$\gamma 2_{\mathrm{C} 2}$ & 14.85 & $78.55 * * *$ & $28.92 * * *$ & & & & & & \\
\hline$\gamma 1_{1}$ & 3.02 & $18.96 * * *$ & 6.10 & & & & & & \\
\hline$\gamma 1_{2}$ & $19.35 * * *$ & $24.60 * * *$ & $9.63 * *$ & & & & & & \\
\hline$\gamma 1_{3}$ & 3.41 & 84.07 *** & $19.61 * * *$ & & & & & & \\
\hline$\gamma 1_{4}$ & 5.57 & 91.14 **** & $26.51 * * *$ & & & & & & \\
\hline$\gamma 1_{5}$ & $9.28 * *$ & $22.35 * * *$ & $14.17 * * *$ & & & & & & \\
\hline$\gamma 1_{6}$ & $13.15 * * *$ & $41.51 * * *$ & $9.10 * *$ & & & & & & \\
\hline$\gamma 1_{7}$ & $15.64 * * *$ & $15.62 * * *$ & $10.85 * *$ & & & & & & \\
\hline$\gamma 1_{8}$ & $7.83 *$ & $75.78 * * * *$ & $23.72 * * *$ & & & & & & \\
\hline$\gamma 1_{9}$ & $8.71 *$ & $39.27 * * *$ & $14.28 * * *$ & & & & & & \\
\hline$\gamma_{1}$ & 6.16 & $45.91 * * *$ & $28.42 * * *$ & & & & & & \\
\hline$\gamma_{2}$ & 5.80 & $62.29 * * * *$ & $11.81 * *$ & & & & & & \\
\hline$\gamma_{3}$ & 2.66 & $28.13 * * *$ & $14.92 * * *$ & & & & & & \\
\hline$\gamma_{4}$ & 2.76 & $60.05 * * *$ & $7.19 *$ & & & & & & \\
\hline$\gamma_{5}$ & 6.62 & $37.99 * * *$ & $21.96 * * *$ & & & & & & \\
\hline$\gamma_{6}$ & $7.42 *$ & $34.15 * * *$ & $9.44 * *$ & & & & & & \\
\hline$\gamma_{7}$ & 3.39 & $13.20 * * *$ & $8.05 *$ & & & & & & \\
\hline$\gamma_{8}$ & 2.98 & $19.30 * * *$ & 5.41 & & & & & & \\
\hline$r_{9}$ & 5.09 & $50.19 * * *$ & 4.08 & & & & & & \\
\hline$\gamma 2_{10}$ & $8.20 *$ & $36.19 * * *$ & 6.32 & & & & & & \\
\hline$\gamma 2_{11}$ & 4.70 & $14.78 * * * *$ & $10.49 * *$ & & & & & & \\
\hline$\gamma 2_{12}$ & 5.75 & $10.59 * *$ & $11.64 * *$ & & & & & & \\
\hline$\beta_{\mathrm{ALL}}$ & $15.08 * *$ & $78.18 * * *$ & $29.72 * * *$ & & & & & & \\
\hline$\beta_{1}$ & $11.60 * * *$ & $9.01 * *$ & $26.41 * * *$ & & & & & & \\
\hline$\beta_{2}$ & $9.01 * *$ & $76.10 * * *$ & $8.22 *$ & & & & & & \\
\hline$\beta_{3}$ & 6.06 & $18.98 * * *$ & $13.55 * * *$ & & & & & & \\
\hline
\end{tabular}




\section{Liste des publications au CIRANO .}

\section{Cahiers CIRANO / CIRANO Papers (ISSN 1198-8169)}

96c-1 Peut-on créer des emplois en réglementant le temps de travail ? / par Robert Lacroix

95c-2 Anomalies de marché et sélection des titres au Canada / par Richard Guay, JeanFrançois L'Her et Jean-Marc Suret

95c-1 La réglementation incitative / par Marcel Boyer

94c-3 L'importance relative des gouvernements : causes, conséquences et organisations alternative / par Claude Montmarquette

94c-2 Commercial Bankruptcy and Financial Reorganization in Canada / par Jocelyn Martel

94c-1 Faire ou faire faire : La perspective de l'économie des organisations / par Michel Patry

\section{Série Scientifique / Scientific Series (ISSN 1198-8177)}

97s-04 La régie des services informatiques : Le rôle de la mesure et des compétences dans les décisions d'impartition / Benoit A. Aubert, Suzanne Rivard et Michel Patry

97s-03 Competition and Access in Telecoms: ECPR, Global Price Caps, and Auctions / Marcel Boyer

97s-02 L'économie des organisations : Mythes et réalités / Marcel Boyer

97s-01 Fixed Wages, Piece Rates, and Intertenporal Productivity: A Study of Tree Planters in British Columbia / Harry J. Paarsch et Bruce Shearer

96s-34 Structural Change and Asset Pricing in Emerging Markets / René Garcia et Eric Ghysels

96s-33 Monitoring of Pollution Regulation: Do Local Conditions Matter? / Catherine Dion, Paul Lanoie et Benoit Laplante

96s-32 Technological Learning and Organizational Context: Fit and Performance in SMEs / Élisabeth Lefebvre, Louis A. Lefebvre et Lise Préfontaine

96s-31 Piece Rates, Fixed Wages, and Incentive Effects: Statistical Evidence from Payroll Records / Harry J. Paarsch et Bruce Shearer

96s-30 R\&D Spillover and Location Choice under Cournot Rivalry / Ngo Van Long et Antoine Soubeyran

96s-29 Efficient Income Redistribution in a Growing Economy / Gerhard Sorger

96s-28 Wage Flexibility and Contract Structure in Germany / Lars Vilhuber

96s-27 Setting Standards for Credible Compliance and Law Enforcement / Marcel Boyer, Tracy R. Lewis et Wei Len Liu

96s-26 American Options with Stochastic Dividends and Volatility: A Nonparametric Investigation / Mark Broadie, Jérôme Detemple, Eric Ghysels et Olivier Torrès

96s-25 How Did Ontario Pulp and Paper Producers Respond to Effluent Regulations, 1985-89? / Paul Lanoie, Mark Thomas et Joan Fearnley

*Vous pouvez consulter la liste complète des publications du CIRANO et les publications elles-mêmes sur notre site World Wide Web à l'adresse suivante :

http://www.cirano.umontreal.ca/publication/page1.html 